\author{
R. Żebrowski ${ }^{1}$, M. Walczak ${ }^{2 *}$ \\ ${ }^{1}$ Center of Oncology of the Lublin Region St. John of Dukla, Department of General Surgery, \\ Lublin, Poland \\ ${ }^{2}$ Lublin University of Technology, Faculty of Mechanical Engineering, Department of \\ Materials Engineering, Lublin, Poland \\ *m.walczak@pollub.pl
}

\title{
THE EFFECT OF SHOT PEENING ON THE CORROSION BEHAVIOUR OF Ti-6Al-4V ALLOY MADE BY DMLS
}

\begin{abstract}
Additive Manufacturing processes are being used increasingly in the scope of medicine and dentistry. As indicated by literature data, the durability and quality of medical implants is decisively influenced by surface modification. Insufficient quality of surface finishing leads, among others, to reduced service life of applied implants and to increased number of necessary revision surgeries. Furthermore, various types of finishing processes e.g. cleaning, shot peening or abrasive techniques are suggested by the manufacturers of products made by means of DMLS processes. Due to this fact, the analysis of proper formation of the surface layer of titanium products made by means of the method consisting in the direct laser sintering of metal powders (DMLS) was the subject matter of our research. Therefore, Ti-6Al-4V titanium alloy has been used for tests. The samples have been produced by means of EOSINT M280 system dedicated for laser sintering of metal powders. The surfaces of prepared samples have been subjected to shot peening process at three different values of working pressure $(0.2,0.3$ and $0.4 \mathrm{MPa})$ by means of three different working media i.e. CrNi steel shot, crushed nut shells and ceramic balls. The characteristics of the materials used for shot peening process have been determined by means of Zeiss Ultra Plus scanning electron microscope. The samples have been subjected to profilometric measurements on Bruker Contour GT optical profilometer and the corrosion behaviour of Ti-6Al$4 \mathrm{~V}$ titanium alloy in Ringer solution has been determined in electrode impedance spectroscopy (EIS) measurements by means of Atlas 0531 set dedicated for corrosion testing. The overall results of all tests indicate to favourable influence of the shot peening process on the corrosion behaviour of titanium alloy.
\end{abstract}

Keywords: Additive Manufacturing, titanium, shot peening, corrosion behaviour

\section{INTRODUCTION}

Titanium alloys fully meet the requirements defined for metallic biomaterials due to their high biotolerance, proper mechanical properties and high corrosion resistance in tissues and body fluids environment [1-4]. However, in spite of their favourable properties, some defects of metallic implants are observed for in vitro conditions - mainly occurring in surface layer as 
a result of combined processes associated with wear and corrosion [5,6]. Metallosis and implant damage caused by insufficient finishing quality of implant surface constitute an important clinical problem leading to the necessity to carry out revision surgeries which additionally create the discomfort feeling in the patient $[5,7]$.

Titanium implants with complicated shapes can be fabricated by means of conventional technologies in the form of casting, plastic forming or material removal processing [8] Recently we have seen intensive development in the scope of Additive Manufacturing (AM) associated with fabrication of personalized implants made of Ti-6Al-V alloy [8,9]. AM processes are well suited when it is necessary to customize a specified implant to anatomic conditions of the patient or to produce such implant on the request or to produce porous or cellular structures with proper mechanical strength and high resistance in body fluids environment. The manufacturers of the systems dedicated for laser sintering of metal powders suggest various types of finishing processes for the products produced by means of 3D printing e.g. cleaning, abrasive techniques or shot blasting. Direct Metal Laser Sintering technology itself causes the generation of residual stresses in the products. Therefore, shot peening process is particularly recommended for such type of products. The shot peening process leads to increased strength of metallic elements as a result of strengthening of the surface layer [10]. At the moment, there are no detailed technological guidelines for such for medical products produced in AM processes i.e. size and shape of shot grains or shot type, working pressure or kind of material used for shot production. However, for the products obtained as a result of AM technologies dedicated for application in engineering e.g. in aircraft industry, steel shot, nutshells or ceramic beads are used very often. In case of products fabricated for medical applications characterized by a high level of technological regime, the are no defined guidelines applicable to forming of surface layer in such products. Whereas, in accordance with the authors' own research and source literature [2], as a result of shot peening process, shot grains can penetrate into subsurface layer (depositing permanently) and change the corrosion resistance of modified products. Therefore, all experimental studies associated with assessment of the technical condition of products contribute to the improvement of their durability $[11,12]$.

Recently, the majority of research works has been focused on mechanical and structural properties and the impact of surface layer modification as a result of shot peening process on corrosion properties was neglected. Therefore, the purpose of our research was to modify the surface layer of titanium specimens produced by means of Direct Metal Laser Sintering process in the context of improvement of material behaviour in simulated body fluids impact environment.

\section{EXPERIMENTAL}

\section{Specimens preparation}

The specimens have been made of gas atomized powder of Ti-6Al-4V alloy with almost spherical shape and chemical composition meeting the requirements of ASTM F1472 (Fig. 1a) in the scope of maximum content of impurities. The specimens shaped in the form of discs with diameter of $12 \mathrm{~mm}$ and thickness of $3 \mathrm{~mm}$ have been made by means of DMSL technique using EOSINT M280 system (EOS GmbH, Germany) dedicated for laser sintering 
of metal powders. The most important printing parameters are, among other things, distance between paths of $0.1 \mathrm{~mm}$, laser beam speed of $1250 \mathrm{~mm} / \mathrm{s}$, the thickness of melted powder layers of $30 \mu \mathrm{m}$ and applied power of laser beam of $170 \mathrm{~W}$.

Outer surfaces of specimen face in horizontal plane X-Y have been subjected to shot peening process on Peenmatic micro 750 S device (IEPCO, Switzerland) by means of three different media i.e. CrNi steel shot, nutshell granules and ceramic beads. The time of surface treatment was equal to $60 \mathrm{~s}$ and the distance between the nozzle and the face of surface being processed $\sim 25 \mathrm{~mm}$. The principal parameters of materials used in shot peening process are specified in Table 1. The characteristics of the materials used in the shot peening process have been determined by means of electron scanning microscope Quanta 650 (FEI, Holland) and microphotographs are presented on Fig. 1b-d.

The products obtained directly after sintering (without surface modification) have been used as reference specimens.
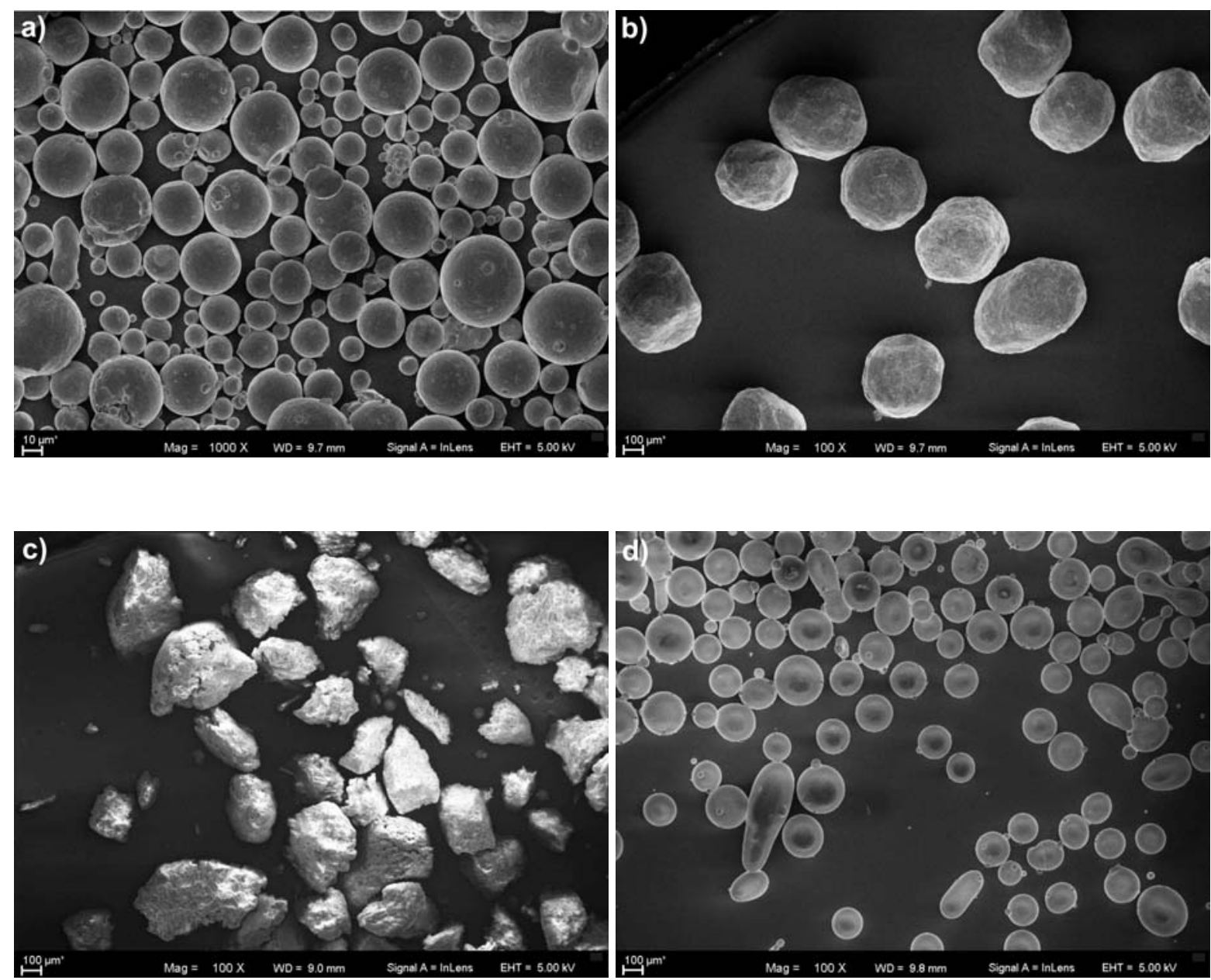

Fig. 1. SEM micrograph of: a) Ti-6Al-4V powder, b) stainless steel shot, c) nutshell granules, d) ceramic beads 
Table 1. Parameters of shot for shot peening

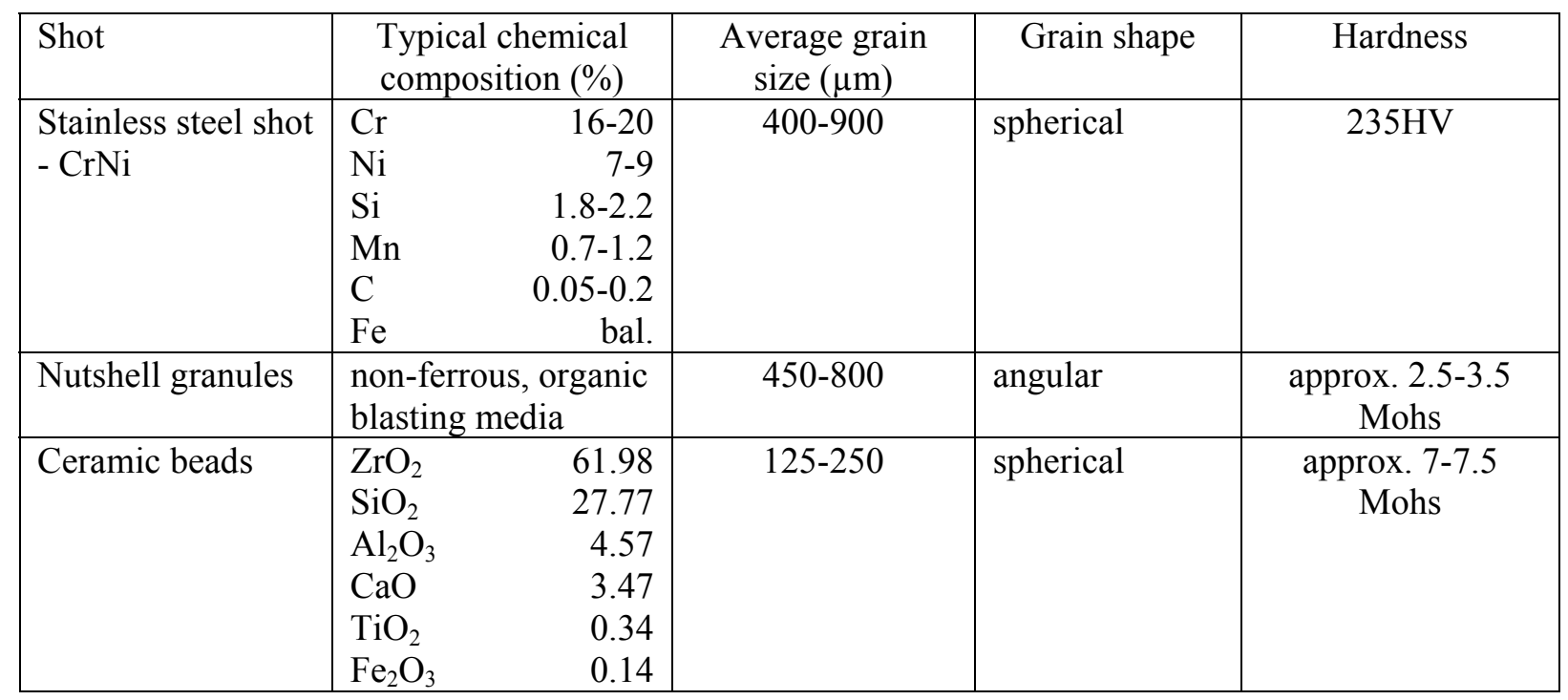

\section{Experimental procedures}

The specimens to be tested have been subjected to profilometric measurements on Contour GT optical profilometer (Bruker, Germany). The measurements were carried out under magnification 5.5x. The profilometric analysis encompassed the surface area of $25 \mathrm{~mm}^{2}$ using VSI method (Vertical Scanning Interferometry) and obtained signals have been converted by means of Bruker Vision64 software.

The corrosion behaviour of specimens has been determined by means of EIS measurements (electrode impedance spectroscopy) in Ringer solution $\left(\mathrm{pH}=7.2\right.$, at $37{ }^{\circ} \mathrm{C}$ ) using Atlas 0531 set dedicated for corrosion tests. The tests were carried out in an electrochemical vessel with three electrodes i.e. with platinum electrode applied as control electrode and saturated calomel electrode (SCE) applied as reference electrode. The surface area of electrode being tested was equal to $1 \mathrm{~cm}^{2}$. The specimens were immersed in corrosive medium for the period of $3600 \mathrm{~s}$ before EIS measurements. The EIS studies were conducted in the frequency range of $100 \mathrm{kHz} \div 100 \mathrm{mHz}$, with a potential sine wave amplitude of $10 \mathrm{mV}$ (rms). Testing parameters have been assumed in accordance with parameters available in source literature $[5,13,14]$. The results analysis was carried out in AtlasLab program. Impedance spectra determined for titanium specimens with properly modified surface have used as the basis for development of an equivalent electric circuit.

\section{RESULTS AND DISCUSSION}

\section{Morphology and geometrical structure of surface}

The process of products manufacturing in DMLS technology takes place along the laser beam scanning direction on the surface of thin layer of powder deposited on the substrate (base plate). Therefore, as a result surface tension of melted material, a laser melted track is created (Fig. 2a) which represents the laser operation direction. The laser beam penetration into substrate or to the previously sintered layer provides an additional stabilizing effect for continuous creation of paths [15] but excessive penetration of keyhole is unfavourable, 
because such phenomenon can generate the pores in the product. Furthermore, a phenomenon associated with collapsing of welding puddle is possible in surface layer which generates structural discontinuities (Fig. 2a), and in accordance with the research [16] gas bubbles in material can be generated additionally. In the opinion of Yadroitsev et al. [17] a deeper penetration of laser beam (the depth of weld penetration) penetrating significantly deeper than the thickness of sintered layer is also undesirable for energy reasons.

On the outer surface in X-Y plane (Fig. 2b) it was possible to observe a few places with not wholly melted titanium powder grains. In case of untreated surfaces, the structural discontinuities and not fully melted powder grains can act as micro-notches. In such case, under the influence of variable external load and corrosive impact of body fluids environment, they can constitute the areas of micro-cracks development situated in surface layer and consequently reducing strength parameters of the whole implant.
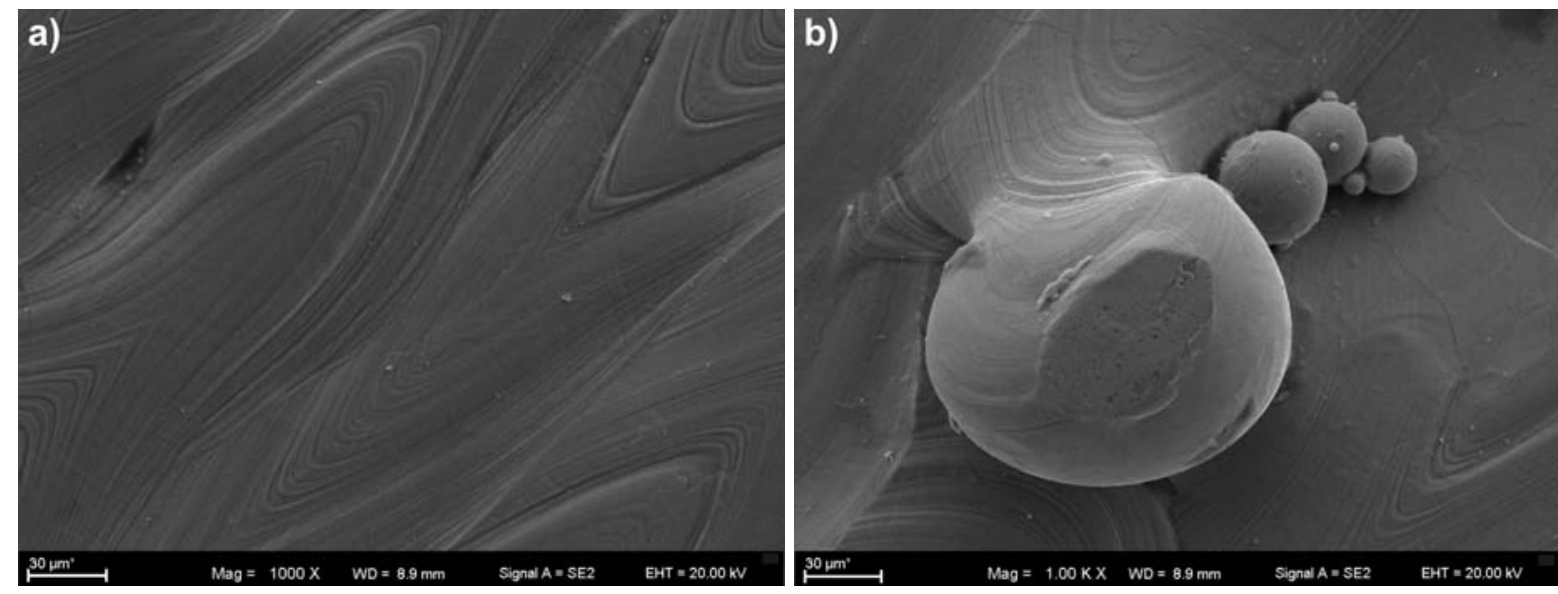

Fig. 2. SEM microphotographs illustrating the morphology of specimens surface after sintering by means of DMSL technology: a) visible laser beam scanning directions with structural discontinuity, b) partially melted titanium powder grains

As described in source literature $[9,10,18] \mathrm{Sa}$ - arithmetic average of surface roughness is usually used for the evaluation of surfaces subjected to shot peening process as the most representative parameter for surfaces after shot peening. In the present study, Sp and Sv roughness parameters have been additionally subjected to analysis i.e. maximum profile peak height of the roughness profile and maximum profile valley depth of the roughness profile correspondingly. On the basis of analysis of the results obtained from profilometric measurements Table 2, it is possible to observe an increase of surface development with the increase of working pressure in the shot peening process for all modified surfaces. The shot peening process leads to increased roughness resulting from high energy of shot impact causing indentations on the surface.

The studies [18] confirm that the increase of working pressure at constant grain size leads to roughness increase and roughness profile created in such circumstances is linearly proportional to the velocity of impact intensity $[10,19]$.

The analysis of roughness parameters indicated that the shot peening process by means of CrNi steel shot as well as by means of ceramic beads causes the reduction of roughness in relation to unmodified surface (obtained directly after DMLS sintering). However, in case of surface modification by means of nutshell granules, observed roughness increase is greater than in case of an unmodified surface. Such behaviour is associated with irregular sharpedged shape of used grains while $\mathrm{CrNi}$ steel shot and ceramic beads were almost spherical. 
Additionally, in case of surfaces treated by means of steel shot and ceramic beads, the increase of all parameters i.e. Sa, Sp and Sv subjected to analysis has been observed at working pressure increase. The increase of working pressure causes large impact indentations manifesting themselves in the form of significant increase of $\mathrm{Sv}$ parameter for all cases subjected to analysis (various types of shot material).

Table 2. Summary of measured surface parameters i.e. Sa, Sp, Sv $(\mu m)$ for surfaces being tested

\begin{tabular}{|c|l|l|l|c|}
\hline $\begin{array}{c}\text { Peening } \\
\text { pressure } \\
(\mathrm{MPa})\end{array}$ & \multicolumn{1}{|c|}{ Steel CrNi } & \multicolumn{1}{|c|}{ Nuts } & \multicolumn{1}{|c|}{ Ceramics } & Unmodified surface after DMLS \\
\hline & $\mathrm{Sa}=5.015$ & $\mathrm{Sa}=7.641$ & $\mathrm{Sa}=6.106$ & \\
\hline & $\mathrm{Sp}=76.347$ & $\mathrm{Sp}=96.725$ & $\mathrm{Sp}=57.71$ & \\
& $\mathrm{~Sv}=-50.017$ & $\mathrm{~Sv}=-108.239$ & $\mathrm{~Sv}=-40.53$ & \\
\hline & $\mathrm{Sa}=6.381$ & $\mathrm{Sa}=7.829$ & $\mathrm{Sa}=6.595$ & $\mathrm{Sa}=7.483$ \\
0.3 & $\mathrm{Sp}=101.249$ & $\mathrm{Sp}=92.89$ & $\mathrm{Sp}=101.378$ & $\mathrm{Sp}=96.573$ \\
& $\mathrm{~Sv}=-79.16$ & $\mathrm{~Sv}=-115.494$ & $\mathrm{~Sv}=-79.968$ & $\mathrm{~Sv}=-70.374$ \\
\hline & $\mathrm{Sa}=6.904$ & $\mathrm{Sa}=7.877$ & $\mathrm{Sa}=6.953$ & \\
& $\mathrm{Sp}=108.033$ & $\mathrm{Sp}=76.36$ & $\mathrm{Sp}=100.649$ & \\
& $\mathrm{~Sv}=-125.949$ & $\mathrm{~Sv}=-134.364$ & $\mathrm{~Sv}=-116.63$ & \\
\hline
\end{tabular}

Moreover, at lower average size of ceramic beads (almost three times) in comparison to $\mathrm{CrNi}$ steel shot at working pressure of $0.2 \mathrm{MPa}$ it is possible to achieve higher roughness parameters Sa (Table 2). Smaller shot grain size leads to reduced indentation size after shot peening process but it is translated into increased number of indentations per surface unit.

Different changes are observed in case of surfaces treated by means of nutshell granules. In this case, $\mathrm{Sv}$ parameter increases at the increase of working pressure and $\mathrm{Sp}$ parameter is reduced. Therefore, in case of sharp-edged shot, the intensity of created indentations is significantly greater than in case of spherical $\mathrm{CrNi}$ and ceramic grains.

The differences in the values of Sa, Sp and Sv parameters between the surfaces tread by means of CrNi steel shot and ceramic beads correspondingly and the pressures of 0.3 and 0.4 $\mathrm{MPa}$ found in course of analysis are not significant. The amount of shot hitting the surface being treated is increased at higher pressure and the reinforcement of shot material (reduction of grain size and hardness increase) takes place in case of $\mathrm{CrNi}$ steel shot. In the opinion of shot manufacturer (Kuhmichel), even double increase of grain hardness is possible from $235 \mathrm{HV}$ to $460 \mathrm{HV}$. The hardness of ceramic beads is much higher than the hardness of titanium substrate. Therefore its geometry in course of shot peeling process is not changed. The average increase of roughness parameter Sa by about $0.3 \div 0.4 \mu \mathrm{m}$ is observed at constant increase of working pressure by $0.1 \mathrm{MPa}$.

The topography of surface being treated is modified by shot grains penetrating into surface layer of Ti-6Al-4V alloy. Such process is particularly visible for surfaces modified at working pressure of $0.4 \mathrm{MPa}$ (Fig. 3). Penetrating shot is located in structural discontinuities or directly on the surface as a result of its high kinetic energy because the properties of material being printed contribute to such behaviour. Ti-6Al-4V alloy belongs to materials characterized by high ductility and plasticity with high reactivity which contributes to spontaneous oxidation of surface layer. Protective properties of passive layer depend mainly on its chemical composition, structure, thickness and potentially occurring defects. Therefore, greater surface roughness and shot inclusions can affect the corrosion resistance of medical implants. 

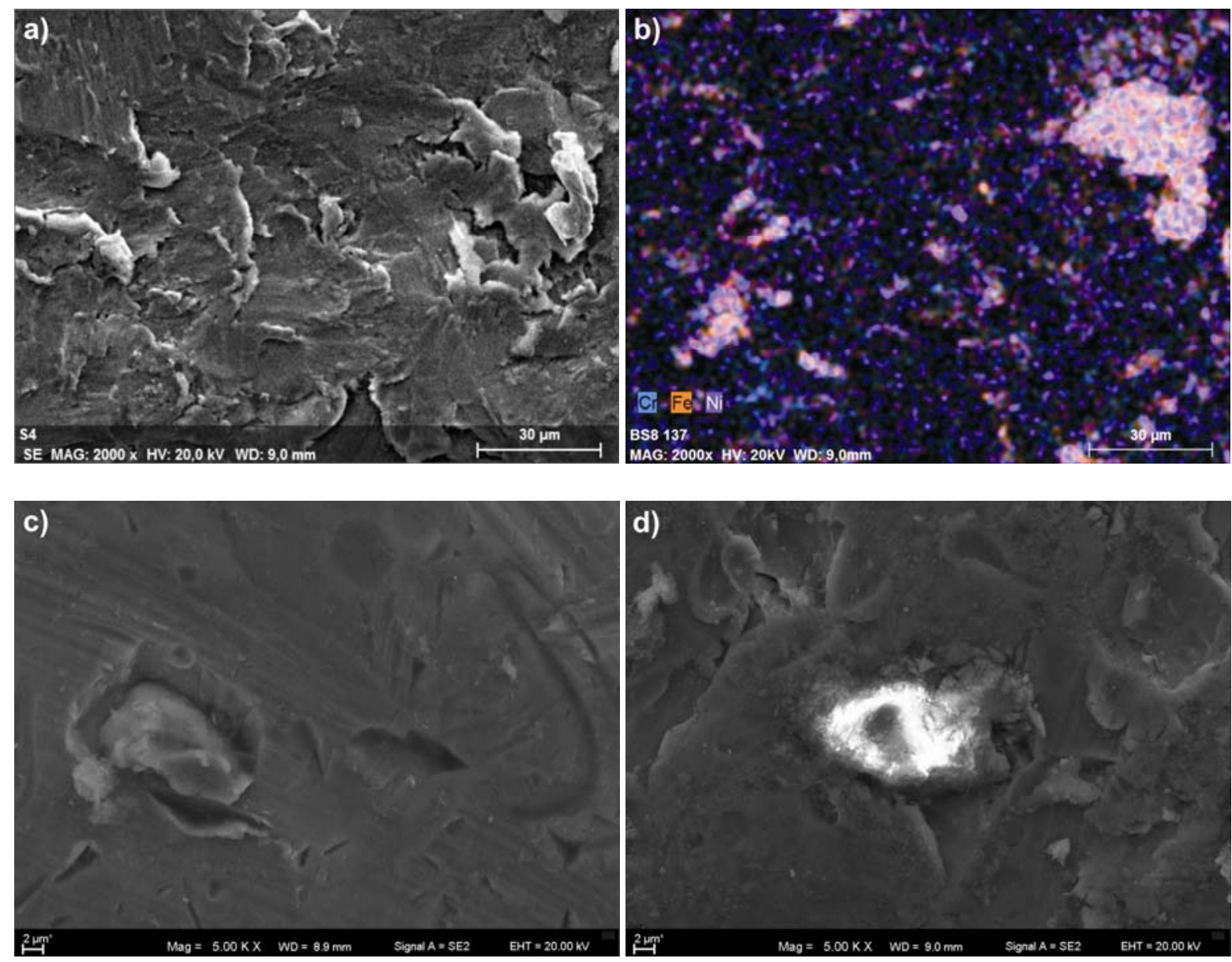

Fig. 3. SEM microphotographs illustrating the shot inclusions on specimens surface (shot made of CrNi steel, b) mapping of elements originating from steel shot - $\mathrm{Cr}, \mathrm{Fe}, \mathrm{Ni}, \mathrm{c}$ ) nutshell granules, d) ceramic beads

\section{Corrosion behaviour}

The equivalent electric circuit for experimental data has been shown on Fig. 4. This circuit is constituted by a constant phase element $\left(\mathrm{CPE}_{1}\right)$, used to simulate a non-ideal behaviour of the condenser due to the passive of the oxide layer, the electrolyte resistance $\left(R_{s}\right)$, and the charge transfer resistance $\left(R_{1}\right)$. The simulated values are included in Table 3 . From the results analysis it appears that the value of $\mathrm{R}_{1}$ resistance decreases with the increasing pressure of shot peening process for all modified surfaces. High value of $R_{1}$ resistance results in higher corrosion resistance. The most favourable resistance values have been obtained for ceramic beads. Higher values of $R_{1}$ resistance for surfaces modified with steel shot and ceramic beads in comparison the surface obtained directly after DMLS process are associated with the creation of passive layer in Ringer solution. It has been demonstrated in other experiments [5]. The highest value of $\mathrm{R}_{1}$ resistance has been recorded for shot peening by means of ceramic beads at the pressure of $0.2 \mathrm{MPa}$. Even in case of ceramic beads penetration into the surface layer, they play the role of insulating material. It is evaluated as neutral in view of biocompatibility. In the opinion of Ahmed et al. [10] the value of corrosion resistance of processed alloys is higher in case of smaller size of shot. It should be reminded that in presented studies the diameter of ceramic beads is more than two times smaller than the diameter of steel shot. It could explain more favourable parameters (higher $\mathrm{R}_{1}$ values) for surfaces modified by means of ceramic beads. 


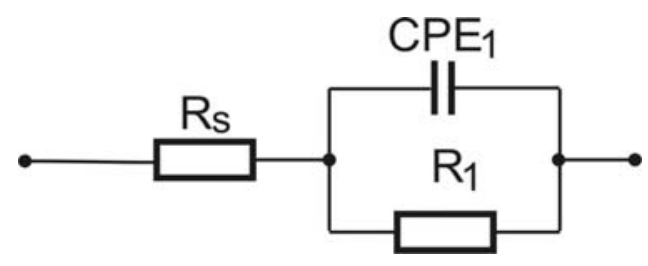

Fig. 4. Equivalent circuit used to fit EIS spectra

Table 3. Results of EIS studies

\begin{tabular}{|c|c|c|c|c|c|}
\hline \multicolumn{2}{|l|}{ Conditions } & \multirow{2}{*}{$\begin{array}{c}\mathrm{R}_{\mathrm{s}} \\
\left(\Omega \cdot \mathrm{cm}^{2}\right)\end{array}$} & \multirow{2}{*}{$\begin{array}{c}\mathrm{R}_{1} \\
\left(\Omega \cdot \mathrm{cm}^{2}\right)\end{array}$} & \multicolumn{2}{|c|}{$\mathrm{CPE}_{1}$} \\
\hline & & & & $\mathrm{Y}_{1}\left(\mathrm{~S} / \mathrm{cm}^{2}\right)$ & $\mathrm{N}_{1}$ \\
\hline \multirow{3}{*}{ Cr-Ni steel } & $0.2 \mathrm{MPa}$ & 31.45 & $1278.40 \mathrm{e}+2$ & $102.20 \mathrm{e}-6$ & 0.84 \\
\hline & $0.3 \mathrm{MPa}$ & 29.59 & $1010.44 \mathrm{e}+1$ & $128.01 \mathrm{e}-6$ & 0.82 \\
\hline & $0.4 \mathrm{MPa}$ & 29.11 & $528.75 \mathrm{e}+1$ & 26.26 e- 6 & 0.91 \\
\hline \multirow{3}{*}{ Nuts } & $0.2 \mathrm{MPa}$ & 30.21 & $925.98 \mathrm{e}+1$ & $30.71 \mathrm{e}-6$ & 0.88 \\
\hline & $0.3 \mathrm{MPa}$ & 32.38 & $555.34 \mathrm{e}+1$ & 33.00 e- 6 & 0.88 \\
\hline & $0.4 \mathrm{MPa}$ & 32.69 & $539.05 \mathrm{e}+1$ & 33.44 e- 6 & 0.88 \\
\hline \multirow[t]{3}{*}{ Ceramics } & $0.2 \mathrm{MPa}$ & 32.02 & $4970.23 \mathrm{e}+3$ & 95.53 e- 6 & 0.77 \\
\hline & $0.3 \mathrm{MPa}$ & 32.31 & $1096.42 \mathrm{e}+3$ & 119.57 e-6 & 0.81 \\
\hline & $0.4 \mathrm{MPa}$ & 25.32 & $3120.03 \mathrm{e}+1$ & 83.06 e- 6 & 0.82 \\
\hline \multicolumn{2}{|c|}{ DMLS (reference) } & 27.79 & $898.02 \mathrm{e}+1$ & $25.87 \mathrm{e}-6$ & 0.89 \\
\hline
\end{tabular}

Bode plots for modified specimens made of Ti-6Al-4V alloy are shown on Fig. 5. The shapes of impedance spectra (Fig.5 i 6) are very similar for all surfaces being tested and their time constant (phase angle diagram) is the same which indicates to their capacitive characteristics. Bode plot (Fig 5.) for the surface obtained directly after DMLS process is characterized by phase angles of almost $80^{\circ}$ in the scope of medium frequencies which suggests the creation of a compact passive layer on boundary surface. However, phase angles at low frequencies are reduced to about $60^{\circ}$. Such behaviour points to the fact that the layer created on the surface of titanium alloy is defective. Probably such situation is associated with structural discontinuities occurring after 3D printing (see Fig. 2). Higher values of phase angle are observed in the scope of low frequencies for surfaces treated with steel shot or ceramic beads and characterized by surface roughness (see Table 2) lower than the roughness of reference specimens surface (DMLS). This fact points to more compact passive layer occurring on these specimens. Significant reduction of phase angle is observed in the scope of low frequencies for surfaces with roughness similar to or higher than the roughness of reference specimens. This trend is particularly visible in case of surface treatment by means of steel shot at the pressure of $0.4 \mathrm{MPa}$ and in case of all surfaces modified by means of sharpedged nutshells.

Biomaterials like Ti-6Al-4V alloys are protected as a result of thin passive layer spontaneously created on the surface. The passive layer created on Ti-6Al-4V surgical alloys is stable in Ringer fluid solution and is rich mainly in amorphous $\mathrm{TiO}_{2}$ [5]. The thickness of such passive films is usually equal to several nanometers but they constitute a highly protective barrier between the metal surface of alloy and aggressive environment created by body fluids. Ions transfer through a passive film depends mainly on chemical composition of the film, its structure, thickness and potential defects. In shot peening process, a rough surface is created which is susceptible to corrosion in connection with areas of passive film destroyed as a result of shot impact. 

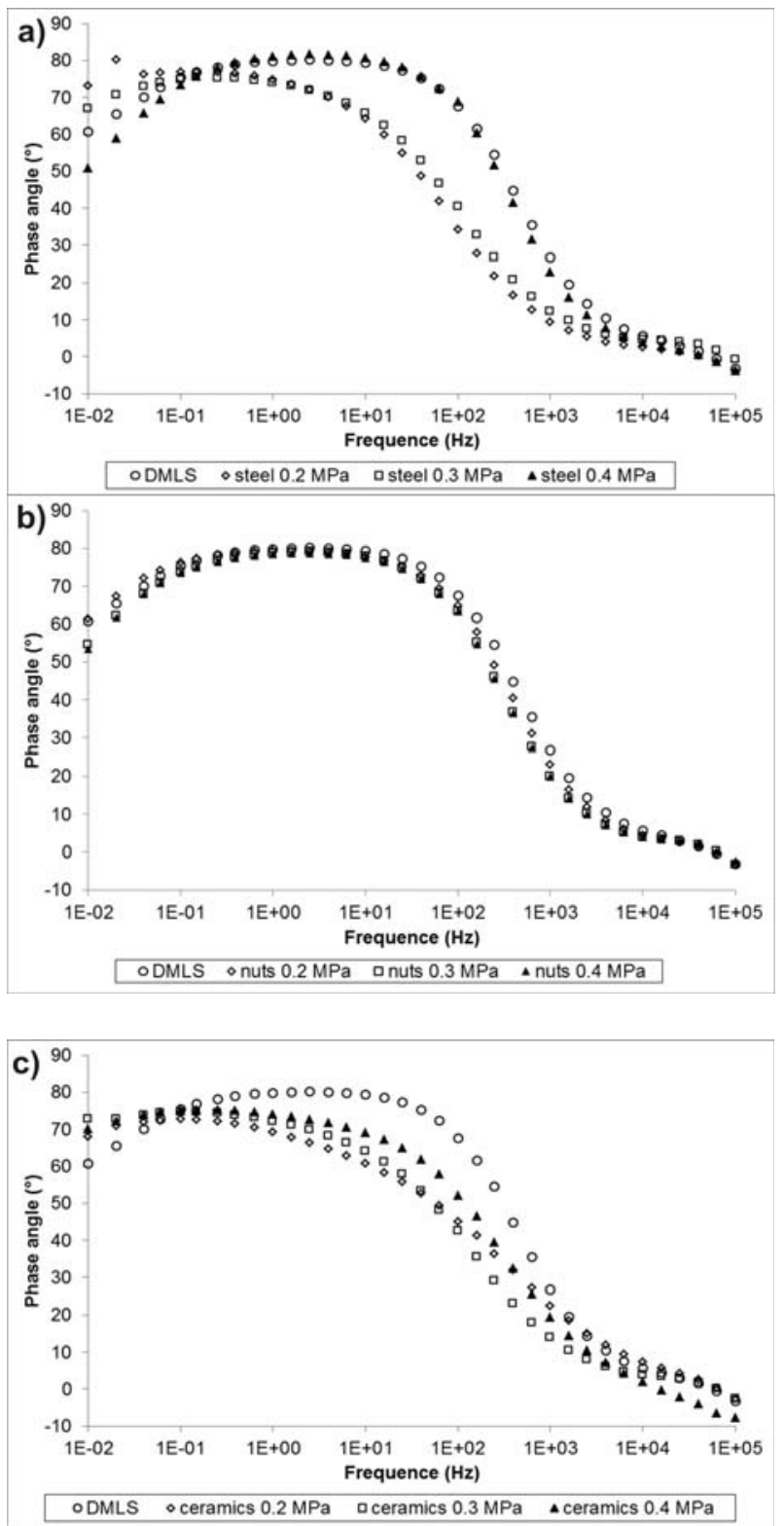

Fig. 5. Bode plot - phase angle vs. frequency for surface modified: a) by means of steel shot, b) by means of nutshells, c) by means of ceramic beads 

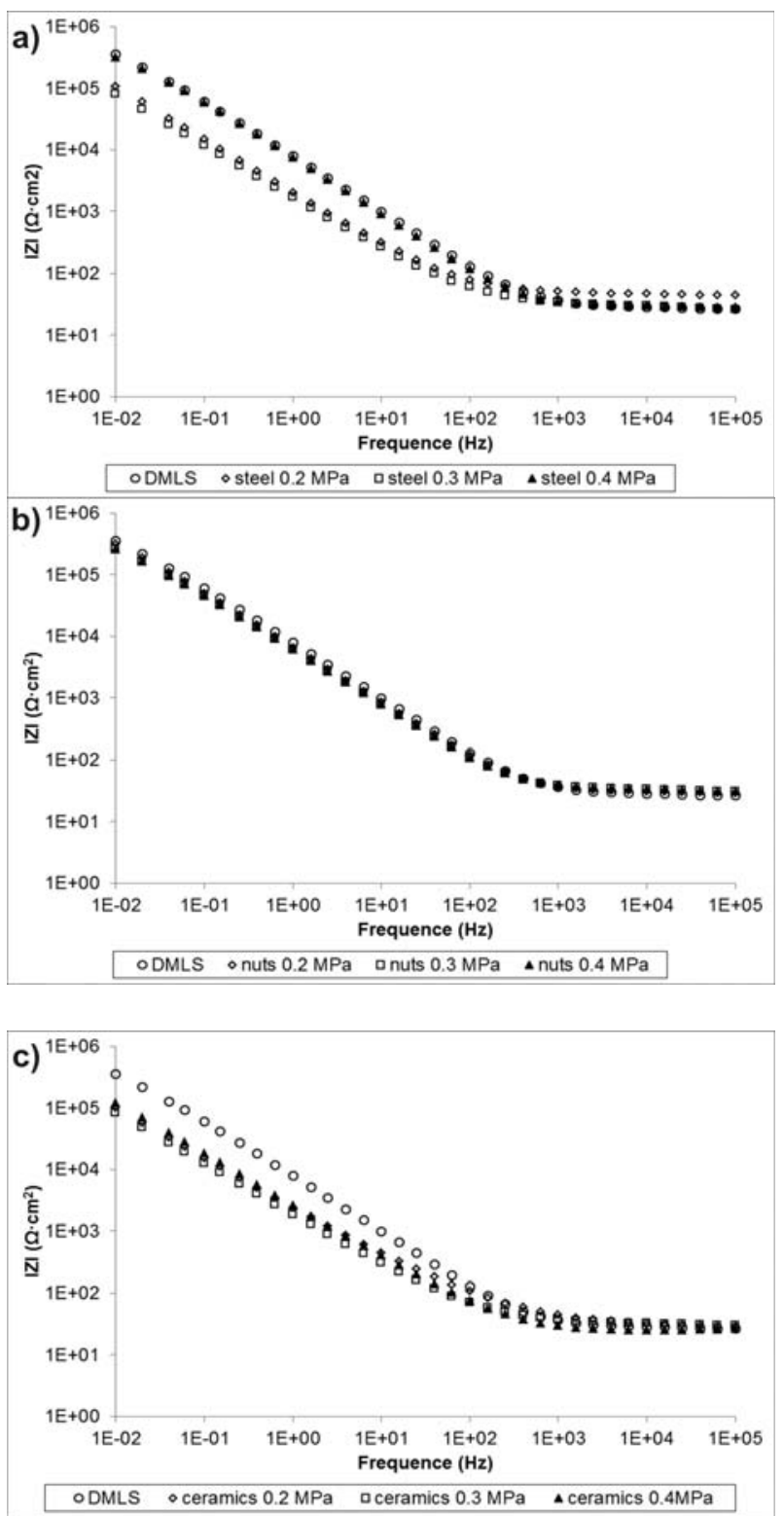

Fig. 6. Bode plot - impedance module vs. frequency for surface modified: a) by means of steel shot, b) by means of nutshells, c) by means of ceramic beads

Impedance spectra (Fig. 6) representing the impedance module vs. frequency indicate to slightly hiver impedance values obtained for DMLS surfaces. However, high impedance has been obtained for all tested surfaces at low frequencies in the range of $10^{5} \div 10^{6} \Omega \cdot \mathrm{cm}^{2}$ which suggests satisfactory corrosion resistance of specimens subjected to shot peening. Such high impedance value are specific for biomaterials with high corrosion resistance in body fluids environment $[5,13,14]$.

\section{CONCLUSIONS}

The main conclusions that can be drawn from this study are: 
- Morphology of surface layer for unmodified specimens obtained directly as a result of DMLS process indicates to the presence of discontinuities associated with the occurrence of not fully melted titanium powder grains and pores.

- Inclusions of particles originating from shot have been observed in the surface layer in case of specimens subjected to shot peening process.

- Increased pressure in range of 0.2-0.4 MPa in course of shot peening process leads to increased surface roughness. Moreover, the increase of $\mathrm{Sa}, \mathrm{Sp}$ and Sv parameters has been observed for steel shot and ceramic beads. However, the increase of Sa and Sv parameters and reduction of Sp parameter has been observed for nutshells which is closely connected with sharp - edged geometry of shot.

- Shot peening process by means of CrNi steel shot as well as by means of ceramic beads causes reduced roughness in comparison with unmodified surface. However, increased roughness in comparison with unmodified surface is observed in case of treatment by means of nutshells.

- The shapes of Bode plots of impedance spectra are very similar to each other for all tested surfaces. However, the values of phase angle were higher in low frequency range in case of surfaces subjected to shot peening by means of steel shot or ceramic beads for which the surface roughness was lower than the roughness of unmodified surfaces.

- In low frequency range, all tested surfaces are characterized by high impedance in the range of $10^{5} \div 10^{6} \Omega \cdot \mathrm{cm}^{2}$ which points to satisfactory corrosion resistance in Ringer solution.

\section{REFERENCES}

1. Bieniaś J., Surowska B., Stoch A., Matraszek H., Walczak M.: The influence of $\mathrm{SiO}_{2}$ and $\mathrm{SiO}_{2-}$ $\mathrm{TiO}_{2}$ intermediate coatings on bond strength of titanium and $\mathrm{Ti6}$ A14V alloy to dental porcelain. Dental Materials 25 (2009) 1128-1135.

2. Geetha M., Singh A.K., Asokamani R., Gogia A.K. Ti based biomaterials, the ultimate choice for orthopaedic implants - A review. Progress in Materials Science 54 (2009) 397-425.

3. Bartmański M.: Properties of nanosilver - doped nanohydroxyapatite coating on the Ti13Zr13Nb alloy. Advances in Materials Science 17 (2017) 18-28.

4. Jażdżewska M., Majkowska- Marzec B.: Hydroxyapatite depositionon the laser modified Ti13Nb13Zr alloy. Advances in Materials Science 17 (2017) 5-13.

5. Jelliti S., Richard C., Retraint D., Roland T., Chemkhi M., Demangel C.: Effect of surface nanocrystallization on the corrosion behavior of Ti-6Al-4V titanium alloy. Surface \& Coatings Technology 224 (2013) 82-87.

6. Walczak M., Drozd K.: Tribological characteristics of dental metal biomaterials. Current Issues in Pharmacy and medical Sciences, Annales Universitatis Mariae Curie-Sklodowska Pharmacia, Sectio DDD 29 (2016) 158-162.

7. Hosoki M., Keisuke N., Youji M., Go O., Yoshizo M.: Allergic contact dermatitis caused by titanium screws and dental implants. Journal of Prosthodontics Research 60 (2016) 213-219.

8. Haruna W.S.W., Manam N.S., Kamariah M.S.I.N., Sharif S., Zulkifly A.H., Ahmad I., Miura H.: A review of powdered additive manufacturing techniques for Ti-6Al-4V biomedical applications. Powder Technology 331 (2018) 74-97.

9. Benedetti M., Torresani E., Leoni M., Fontanari V., Bandini M., Pederzolli C., Potrich C.: The effect of post-sintering treatments on the fatigue and biological behavior of Ti-6Al-4V ELI parts 
made by selective laser melting. Journal of the Mechanical Behavior of Biomedical Materials 71 (2017) 295-306.

10. Ahmed A.A., Mhaede M., Wollmann M., Wagner L.: Effect of micro shot peening on the mechanical properties and corrosion behavior of two microstructure Ti-6Al-4V alloy. Applied Surface Science 363 (2016) 50-58.

11. Fydrych D., Łabanowski J., Tomków J., Rogalski G.: Cold cracking of underwater wet welded S355G10+N high strength steel. Advances in Materials Science 15 (2015) 48-56

12. Vališ D., Koucky M., Zak L.: On approaches for non-direct determination of system deterioration, Eksploatacja i Niezawodnosc - Maintenance and Reliability 14 (2012) 33-41.

13. Saji V.S., Choe H.Ch.: Electrochemical behavior of $\mathrm{Co}-\mathrm{Cr}$ and $\mathrm{Ni}-\mathrm{Cr}$ dental cast alloys. Transactions of Nonferrous Metals Society of China 19 (2009) 785-790.

14. Saji V.S., Choe H.Ch.: Preferential dissolution behaviour in $\mathrm{Ni}-\mathrm{Cr}$ dental cast alloy. Bulletin of Materials Science 33 (2010) 463-468

15. Yadroitsev I. Gusarov A, Yadroitsava I, Smurov I. Single track formation in selective laser melting of metal powders. Journal of Materials Processing Technology 210 (2010) 1624-1631.

16. Thijs L., Kempen K., Kruth J.-P., Van Humbeeck J.: Fine-structured aluminium products with controllable texture by selective laser melting of pre-alloyed AlSi10Mg powder. Acta Materialia 61 (2013) 1809-1819.

17. Yadroitsev I., Krakhmalev P., Yadroitsava I.: Hierarchical design principles of selective laser melting for high quality metallic objects. Additive Manufacturing 7 (2015) 45-56.

18. Ganesh B.K.C., Sha W., Ramanaiah N., Krishnaiah A.: Effect of shotpeening on sliding wear and tensile behavior of titanium implant alloys. Materials and Design 56 (2014) 480-486.

19. Lee H., Kim D., Jung J., Pyoun Y.: Shin K., Influence of peening on the corrosion properties of AISI 304 stainless steel. Corrosion Science 51 (2009) 2826-2830. 